\title{
Evaluation of a Medicaid performance improvement project to reduce high-dose opioid prescriptions
}

\author{
Daniel M. Hartung ${ }^{1,2^{*}}$, Jonah Geddes², Sara E. Hallvik³ ${ }^{3}$ P. Todd Korthuis ${ }^{2}$, Luke Middleton ${ }^{1}$, Gillian Leichtling ${ }^{3}$, \\ Christi Hildebran ${ }^{3}$ and Hyunjee Kim²
}

\begin{abstract}
Background: In 2015, Oregon's Medicaid program implemented a performance improvement project to reduce high-dose opioid prescribing across its 16 coordinated care organizations (CCOs). The objective of this study was to evaluate the effect of that program on prescription opioid use and outcomes.
\end{abstract}

Methods: Using Medicaid claims data from 2014 to 2017, we conducted interrupted time-series analyses to examine changes in the prescription opioid use and overdose rates before (July 2014 to June 2015) and after (January 2016 to December 2017) implementation of Oregon's high-dose policy initiative (July 2015 to December 2015). Prescribing outcomes were: 1) total opioid prescriptions 2) high-dose [>90 morphine milligram equivalents per day] opioid prescriptions, and 3) proportion of opioid prescriptions that were high-dose. Opioid overdose outcomes included emergency department visits or hospitalizations that involved an opioid-related poisoning (total, heroin-involved, non-heroin involved). Analyses were performed at the state and CCO level.

Results: There was an immediate reduction in high dose opioid prescriptions after the program was implemented ( -1.55 prescription per 1000 enrollee; $95 \% \mathrm{Cl}-2.26$ to $-0.84 ; p<0.01)$. Program implementation was also associated with an immediate drop ( -1.29 percentage points; $95 \% \mathrm{Cl}-1.94$ to -0.64 percentage points; $p<0.01)$ and trend reduction ( -0.23 percentage point per month; $95 \% \mathrm{Cl}-0.33$ to -0.14 percentage points; $p<0.01$ ) in the monthly proportion of high-dose opioid prescriptions. The trend in total, heroin-involved, and non-heroin overdose rates increased significantly following implementation of the program.

Conclusions: Although Oregon's high-dose opioid performance improvement project was associated with declines in high-dose opioid prescriptions, rates of opioid overdose did not decrease. Policy efforts to reduce opioid prescribing risks may not be sufficient to address the growing opioid crisis.

Keywords: Opioids, Medicaid, Overdose

\footnotetext{
*Correspondence: hartungd@ohsu.edu

${ }^{2}$ Oregon Health \& Science University, 3181 SW Sam Jackson Park RC,

Portland, Oregon 97239, USA

Full list of author information is available at the end of the article
}

\section{Background}

Despite declines in opioid prescribing, opioid use remains several fold higher today relative to the early 1990s and prescription opioids are still involved in more than one-third of opioid-related deaths in the US $[1,2]$. To confront this public health crisis, federal and state authorities have mounted diverse initiatives such as developing clinical practice guidelines that advocate 
safer opioid prescribing, implementing prescription drug monitoring programs, and advancing legislative or payerbased limits that encourage fewer and/or less risky opioid prescriptions [3]. However, the evidence that interventions and policies to reduce high-risk opioid prescribing are effective at reducing opioid-related overdoses has been mixed [4]. There are also concerns and growing evidence that rapid prescription opioid tapering or discontinuation may be associated with adverse outcomes such as increased use of illicit opioids, suicide, and other opioid-related harms [5-7].

Like the rest of the country, Oregon's opioid-related overdose rate in 2017 was more than twice the rate observed in 2001 [8]. Efforts to address this public health crisis in Oregon have been diverse and included prior authorization for opioid prescriptions exceeding 120 morphine milligram equivalents (MME) that was limited to the fee-for-service program ( $\sim 10 \%$ of Oregon Medicaid population), introduction of Oregon's Prescription Drug Monitoring Program (PDMP) in 2011, and developing evidence-based reviews to support Medicaid coverage standards $[9,10]$. Efforts to expand access to treatment for opioid use disorders during that time period, such as a federal grant to expand medication access in four rural counties that began in 2016, were generally small in scale. Similarly, naloxone access initiatives did not yet have wide reach.

In 2012, Oregon adopted an innovative approach to delivering care through its managed Medicaid program [11]. Oregon's Medicaid program is administered through 16 Coordinated Care Organizations (CCOs), which are community-based healthcare delivery systems that coordinate physical, mental, addictions, and dental care and accept full financial risk for their members, similar to Accountable Care Organizations [11]. As part of this model, CCOs are required to conduct performance improvement projects that can improve care. $\mathrm{CCO}$ administrators collaboratively select the topics and outcome metrics for performance improvement projects. The first performance improvement project was directed at integration of physical and mental healthcare services and evaluated diabetes monitoring in people with serious mental illness [12]. The second statewide project involved prescription opioid safety. Specifically, in July 2015, Oregon's Medicaid program introduced a performance improvement project to reduce high-dose opioid prescribing [12]. Specifically, Oregon's performance improvement project aimed at decreasing the number of Medicaid enrollees filling prescriptions with $\geq 90$ daily morphine milligram equivalents [MME] and $\geq 120$ daily MME, and report back progress meeting those indicators in 2016 and 2017. Although CCOs were required to participate, the state granted CCOs flexibility to develop and implement programs and policies to meet their targets. In response, CCOs adopted various interventions including pharmacy benefit restriction (e.g. quantity limits and prior authorizations on long-acting opioids), provider directed interventions (e.g. training programs and targeted letters), and patient facing education [13].

The objective of this study was to examine trends in opioid prescribing and overdose-related outcomes under the Oregon CCO's opioid performance improvement project that aimed to reduce high-dose opioid prescribing.

\section{Methods}

\section{Data source and sample selection}

We used Oregon Medicaid enrollment files, medical and pharmacy claims to identify patient demographics, health characteristics, prescription opioid use patterns, and rates of overdose. Our study period was July 2014 to December 2017, covering 12 months before and 30 months after the $\mathrm{CCO}$ performance improvement project started in July 2015.

The study sample included non-pregnant adults aged 18-64 with at least 1 month of continuous enrollment in an Oregon Medicaid CCO from 2014 to 2017. We excluded individuals with dual Medicare enrollment, those who resided in a long-term care facility, or had a cancer diagnosis code during the study period [14]. The effects of applying those criteria on the study sample are summarized in Supplemental Fig. 1.

\section{Outcomes}

For each month during the study period, we calculated three prescription opioid use outcomes using pharmacy claims: 1) count of opioid prescriptions dispensed per 1000 enrollees, 2) count of high-dose opioid prescriptions per 1000 enrollees, 3) proportion of opioid prescriptions dispensed with a high-dose. Prescription opioids were identified using National Drug Code identifiers derived from FirstDataBank's Drug File. Consistent with CDC Guideline for Prescribing Opioids for Chronic Pain and the threshold selected for most CCOs, we defined high dose as any prescription exceeding 90 MME per day [13, 15]. We calculated daily MME for each prescription by multiplying the formulation strength by the quantity dispensed and the CDC endorsed conversion factor [16] and then dividing by each prescription's day supply.

We measured rates of opioid overdose using medical claims. We defined opioid overdoses as opioid-related emergency department (ED) encounters or inpatient admissions using International Classification of Disease (ICD) 9th and 10th Revision codes that indicated opioid poisoning as described in Supplemental Table 1. ED encounters were identified in Medicaid medical claims 
using revenue center codes (450-459, 0981). We calculated the number of opioid overdoses overall and separately based on if heroin was involved (ICD9 96,501, E8500; ICD10 T401). Thus, we delineated three opioid overdose outcomes: 1) total opioid overdoses per 100,000 enrollees, 2) heroin-involved overdoses per 100,000 enrollees, and 3) non-heroin involved overdoses per 100,000 enrollees.

\section{Statistical analysis}

We conducted interrupted time series (ITS) regressions to evaluate changes in opioid prescribing and overdose outcomes before and after Oregon's CCO performance improvement project overall and separately for each CCO. Because the initiative was implemented gradually and inconsistently by CCOs, we omitted the first 6 months of the intervention (July 2015 to December 2015) as a transition period. Thus, we ultimately had 12 months of observation before the intervention (July 2014 to June 2015 ) and 24 months of observation after the intervention (January 2016 to December 2017).

We used two sets of ITS regressions. First, we included all $16 \mathrm{CCOs}$ in the regression and evaluated the overall association of the program with outcomes. Second, we stratified the sample by each $\mathrm{CCO}$ and estimated regressions for each $\mathrm{CCO}$ to evaluate heterogeneity across the CCOs. In both sets of regressions, the unit of analysis was CCO-month.

The general form of our ITS regression model was $\mathrm{Y}=\beta_{0}+\beta_{1}{ }^{*}$ PreTrend $+\beta_{2}{ }^{*}$ PIP $+\beta_{3}{ }^{*}$ PostTrend $+\varepsilon t$, where $Y$ is the dependent variable of interest, PreTrend continuous variable to indicate month (1 to 36$)$, PIP indicates if the observation was before or after Oregon's performance improvement project was implemented, and PostTrend is a counting variable to indicate the month after implementation ( 0 if before and 1 to 24 after). $\beta_{1}$ estimates the trend before implementation, $\beta_{2}$ is immediate change following implementation, and $\beta_{3}$ is the change in trend following program implementation. We estimated all ITS regressions based on ordinal least squares with Newey-West standard errors to account for heteroskedasticity. We adjusted for first-degree autocorrelation and we considered 2-tailed $P<0.05$ to be statistically significant.

A secondary objective was to determine if $\mathrm{CCO}$ reductions in high-dose opioid prescribing were associated with reduced opioid overdose. Because overdose events are relatively uncommon and most CCOs enrolled fewer than 100,000 individuals, we grouped CCOs into two groups according to if they experienced a significant reduction in the trend in the proportion of opioid prescriptions over $90 \mathrm{MME}$ per day following the performance improvement project. We then analyzed trends in heroin-involved, non-heroin involved, and total opioid overdose within these two CCO groupings.

We performed all analyses using Stata, version 16 (StataCorp) and conducted our ITS analysis through the user written "itsa" command [17]. The study protocol was performed in accordance with the relevant human subjects guidelines. This study was approved by the institutional review board at the Oregon Health \& Science University. Because this was a retrospective analysis of de-identified data with minimal risks, a waiver of informed consent was granted.

\section{Results}

The final dataset included 584,720 adults across 16 different CCOs. Table 1 summarizes demographic and opioid use characteristics for these individuals. Patient demographics across CCOs were similar in enrollee age and sex, but differed by rural/urban designation, prescription opioid use, high-dose prescription opioid use, and opioid overdose rates. The largest CCOs (Health Share and Family Care) were operating in the Portland Metro region and had 8 and $11 \%$ of their enrollees residing in a rural location, respectively. In contrast, many of the smaller CCOs predominately comprised enrollees living in a rural area. Overall, 9\% prescription opioid users had high dose prescriptions ( $\geq 90$ daily MME), but the prevalence varied more than 3 -fold across CCOs, ranging from 4 to $14 \%$.

Table 2 summarizes estimates from the three ITS regression models. As shown in Fig. 1, the proportion of all opioid prescriptions that were $>=90$ MME declined immediately by 1.29 percentage points ( $95 \%$ CI -1.94 to -0.64 percentage points; $p<0.01$ ). There was also a significant decline in the monthly trend of 0.23 percentage points per month $(95 \% \mathrm{CI}-0.33$ to -0.14 percentage points; $p<0.01$ ). Trends in total opioid and high-dose opioid prescriptions are shown in Supplemental Fig. 2. The trend in total opioids prescription was declining prior to the $\mathrm{CCO}$ initiative at a rate of -2.13 prescriptions per 1000 enrollees per month (95\% CI -2.61 to $-1.65 ; p<0.01)$. Following the implementation of the $\mathrm{CCO}$ initiative, the trend moderated significantly but remained negative. There was an immediate reduction in high dose opioid prescriptions after the $\mathrm{CCO}$ initiative ( -1.55 prescription per 1000 enrollee; $95 \%$ CI -2.26 to $-0.84 ; p<0.01$ ), but no significant change in the overall monthly trend.

Trends in total opioid overdose are presented in Fig. 2 with corresponding ITS regression estimates summarized in Table 3. In the 12 months prior to the CCO initiative, trends in opioid overdose were decreasing significantly. After implementation of the $\mathrm{CCO}$ initiative, there was a significant increase in total opioid overdoses 
Table 1 Enrollee characteristics and prescription opioid use across 16 Coordinated Care Organizations (CCOs) during the preintervention period

\begin{tabular}{|c|c|c|c|c|c|c|c|}
\hline $\mathrm{CCO}$ & Enrollees & $\%$ Female & $\begin{array}{l}\% \text { Rural } \\
\text { residence }\end{array}$ & Mean age (sd) & $\begin{array}{l}\% \text { of enrollees } \\
\text { with any Rx } \\
\text { opioid* }\end{array}$ & $\begin{array}{l}\% \text { of enrollees with an } \\
\text { opioid Rx who had an Rx } \\
\geq 90 \text { MME per day* }\end{array}$ & $\begin{array}{l}\text { Opioid } \\
\text { overdoses per } \\
100,000^{*}\end{array}$ \\
\hline \multicolumn{8}{|l|}{ Portland Metro } \\
\hline Health Share of Oregon & 135,527 & 48 & 8 & $36(11)$ & 10.9 & 9.2 & 21 \\
\hline Family Care & 99,169 & 46 & 11 & $36(11)$ & 6.7 & 7.3 & 20 \\
\hline Columbia Pacific & 18,112 & 49 & 93 & $38(12)$ & 15.4 & 12.2 & 10 \\
\hline \multicolumn{8}{|l|}{ Mid Valley } \\
\hline Yamhill Community Care & 15,015 & 49 & 89 & $37(12)$ & 11.0 & 7.2 & 4 \\
\hline $\begin{array}{l}\text { Willamette Valley Com- } \\
\text { munity Health }\end{array}$ & 50,025 & 48 & 28 & $36(12)$ & 9.6 & 8.8 & 6 \\
\hline $\begin{array}{l}\text { Intercommunity Health } \\
\text { Network }\end{array}$ & 36,080 & 48 & 50 & $36(12)$ & 13.9 & 9.2 & 7 \\
\hline $\begin{array}{l}\text { Trillium Community } \\
\text { Health Plan }\end{array}$ & 60,374 & 48 & 26 & $36(12)$ & 13.6 & 10.6 & 13 \\
\hline \multicolumn{8}{|l|}{ Central / Eastern Oregon } \\
\hline $\begin{array}{l}\quad \text { PacificSource Com- } \\
\text { munity } \\
\text { Solutions CCO Central } \\
\text { Oregon }\end{array}$ & 35,175 & 48 & 55 & $37(12)$ & 11.8 & 4.3 & 9 \\
\hline $\begin{array}{l}\text { PacificSource Com- } \\
\text { munity } \\
\text { Solutions CCO Columbia } \\
\text { Gorge }\end{array}$ & 7502 & 48 & 96 & $38(12)$ & 9.0 & 6.3 & 11 \\
\hline Eastern Oregon CCO & 28,133 & 49 & 97 & $37(12)$ & 15.4 & 9.6 & 6 \\
\hline \multicolumn{8}{|l|}{ Southern Oregon } \\
\hline Cascade Health Alliance & 11,088 & 49 & 95 & $37(12)$ & 7.8 & 3.8 & 2 \\
\hline Umpqua Health Alliance & 17,175 & 47 & 95 & $37(12)$ & 6.3 & 7.9 & 12 \\
\hline $\begin{array}{l}\text { Western Oregon } \\
\text { Advanced Health }\end{array}$ & 13,854 & 48 & 96 & $38(12)$ & 5.9 & 5.4 & 2 \\
\hline AllCare Health Plan & 31,135 & 46 & 58 & $37(12)$ & 5.7 & 7.1 & 12 \\
\hline Jackson Care Connect & 17,722 & 48 & 28 & $36(12)$ & 13.4 & 14.2 & 15 \\
\hline PrimaryHealth & 8634 & 44 & 94 & $37(12)$ & 6.9 & 8.8 & 6 \\
\hline Total & 584,720 & 47.5 & 38.3 & $39(13)$ & 10.4 & 8.9 & 10 \\
\hline
\end{tabular}

CCO Coordinated care organization, MME Morphine milligram equivalent, sd Standard deviation, Rx Prescription

*average monthly rate per 100,000 during baseline period

Table 2 Results from interrupted time series regressions of opioid utilization and opioid overdose outcomes before and during performance improvement project

\begin{tabular}{|c|c|c|c|c|c|c|c|c|c|}
\hline & \multicolumn{3}{|c|}{$\begin{array}{l}\text { Opioid prescriptions per } 1000 \\
\text { enrollees per month }\end{array}$} & \multicolumn{3}{|c|}{$\begin{array}{l}\text { High-dose opioid prescriptions per } \\
1000 \text { enrollees per month }\end{array}$} & \multicolumn{3}{|c|}{$\begin{array}{l}\text { Proportion of opioid prescriptions } \\
\text { that are high dose }\end{array}$} \\
\hline & Coefficient & $95 \% \mathrm{Cl}$ & $p$-value & Coefficient & $95 \% \mathrm{Cl}$ & $p$-value & Coefficient & $95 \% \mathrm{Cl}$ & $p$-value \\
\hline Intercept & 115.89 & 112.37 to 119.41 & $<0.01$ & 19.94 & 19.16 to 20.72 & $<0.01$ & 17.22 & 16.51 to 17.94 & $<0.01$ \\
\hline Baseline trend & -2.13 & -2.61 to -1.65 & $<0.01$ & -0.34 & -0.43 to -0.25 & $<0.01$ & 0.03 & -0.06 to 0.12 & 0.56 \\
\hline Immediate change & -1.07 & -4.85 to 2.71 & 0.57 & -1.55 & -2.26 to -0.84 & $<0.01$ & -1.29 & -1.94 to -0.64 & $<0.01$ \\
\hline Trend change & 1.29 & 0.80 to 1.79 & $<0.01$ & 0.06 & -0.04 to 0.15 & 0.23 & -0.23 & -0.33 to -0.14 & $<0.01$ \\
\hline
\end{tabular}

Cl Confidence interval

(0.57 overdoses per 100,000 enrollees per month; 95\% CI 0.26 to $0.87 ; p<0.01)$. As illustrated in Supplemental Fig. 3, increases in the overdose trend were significant for both heroin-involved ( 0.24 overdoses per 100,000 enrollees per month; $95 \%$ CI 0.01 to $0.47 ; p=0.04$ ) and nonheroin involved overdoses ( 0.40 overdoses per 100,000 


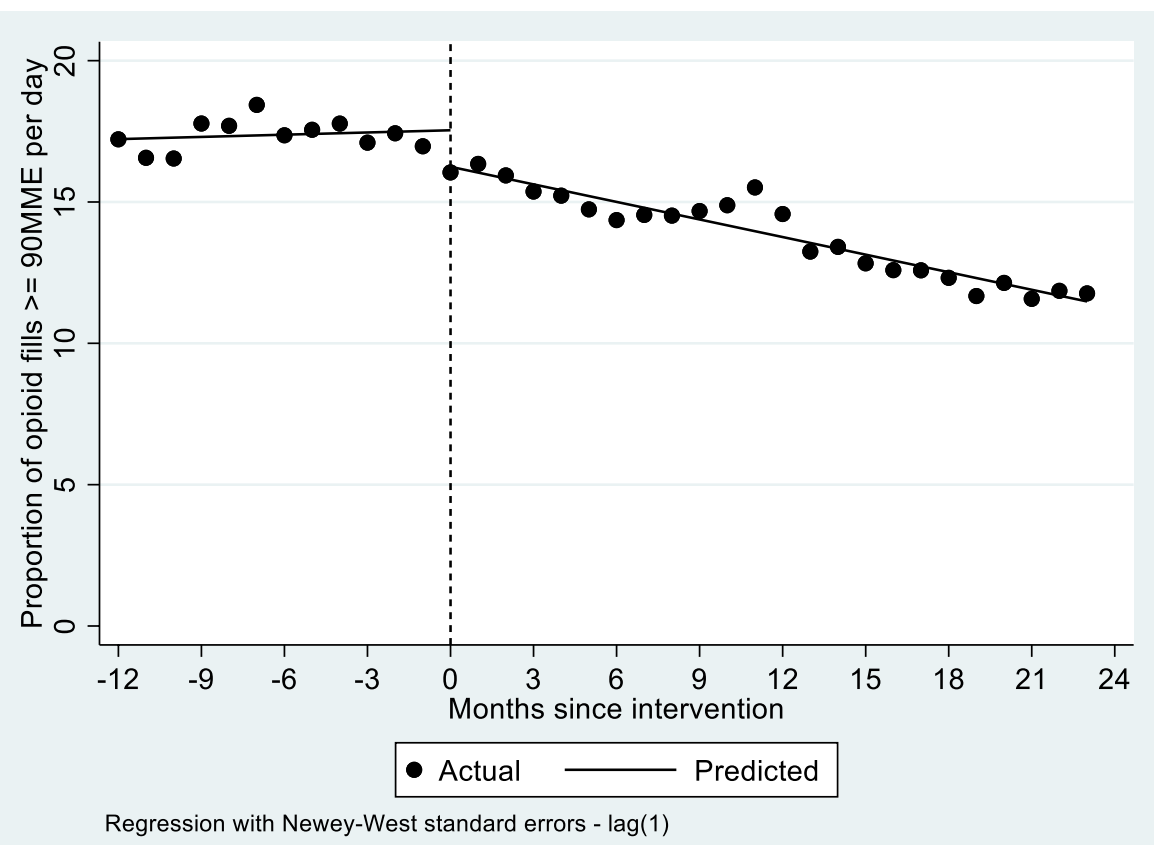

Fig. 1 Interrupted time series regression model of proportion of opioid fills $>=90 \mathrm{MME}$ per day with fitted trend lines before and during performance improvement project. Notes: Dotted line indicates start of performance improvement project

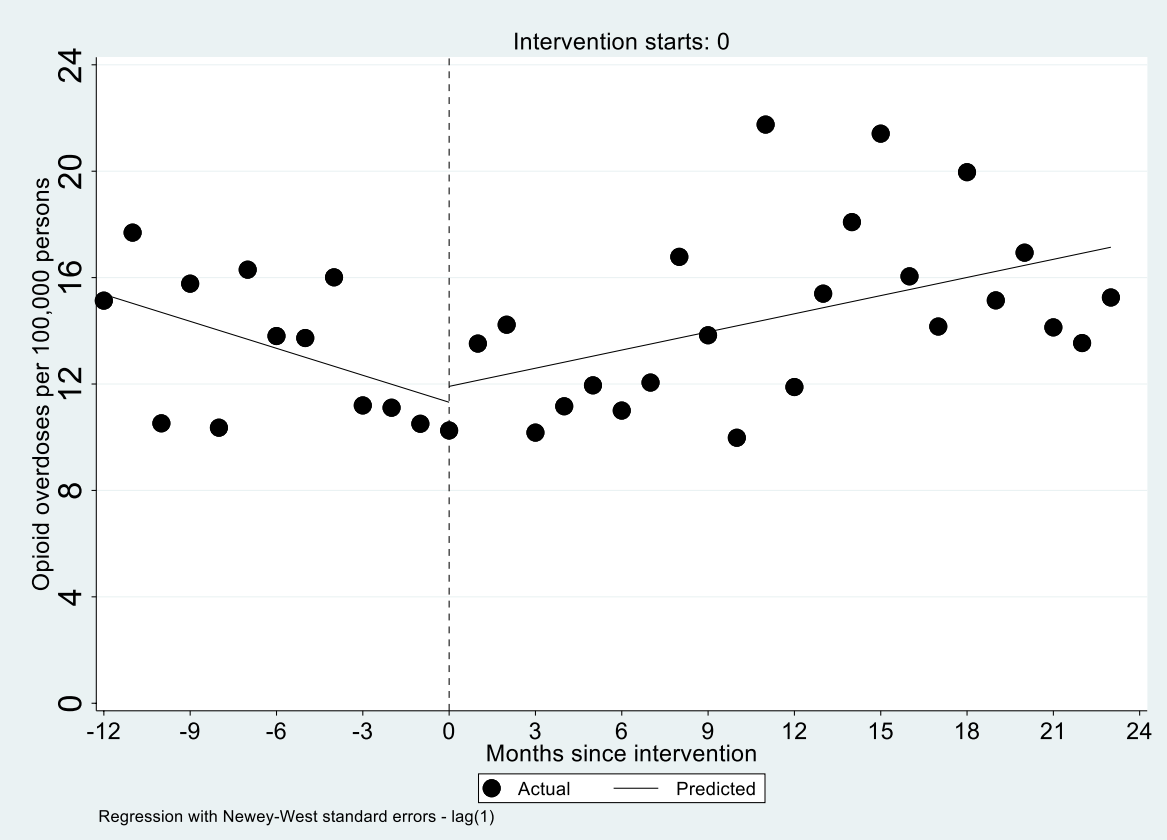

Fig. 2 Interrupted time series regression models of opioid overdose per 100,000 per month with fitted trend lines before and during performance improvement project. Notes: Dotted line indicates start of performance improvement project 
Table 3 Results from interrupted time series regressions of opioid overdose outcomes before and during performance improvement project overall and by Coordinated Care Organizations (CCOs) high dose prescribing changes

\begin{tabular}{|c|c|c|c|c|c|c|c|c|c|}
\hline & \multicolumn{3}{|c|}{ Any Opioid Overdose } & \multicolumn{3}{|c|}{ Heroin-involved } & \multicolumn{3}{|c|}{ Non-heroin involved } \\
\hline & Coefficient & $95 \% \mathrm{Cl}$ & $p$-value & Coefficient & $95 \% \mathrm{Cl}$ & $p$-value & Coefficient & $95 \% \mathrm{Cl}$ & $p$-value \\
\hline \multicolumn{10}{|l|}{ All CCOs } \\
\hline Intercept & 15.37 & 13.71 to 17.03 & $<0.01$ & 8.69 & 7.93 to 9.45 & $<0.01$ & 7.26 & 5.42 to 9.10 & $<0.01$ \\
\hline Pre trend & -0.34 & -0.60 to -0.08 & 0.01 & -0.08 & -0.26 to 0.09 & 0.34 & -0.3 & -0.52 to -0.07 & 0.01 \\
\hline Immediate change & 0.60 & -2.04 to 3.23 & 0.65 & -1.18 & -3.03 to 0.67 & 0.20 & 1.9 & 0.10 to 3.69 & 0.04 \\
\hline Trend change & 0.57 & 0.26 to 0.87 & $<0.01$ & 0.24 & 0.01 to 0.47 & 0.04 & 0.40 & 0.16 to 0.64 & $<0.01$ \\
\hline \multicolumn{10}{|c|}{$10 \mathrm{CCO}$ s with a significant decrease in proportion of opioid fills $>=90 \mathrm{MME}$ per day } \\
\hline Intercept & 17.81 & 15.97 to 19.65 & $<0.01$ & 11.03 & 9.62 to 12.44 & $<0.01$ & 7.53 & 5.43 to 9.62 & $<0.01$ \\
\hline Pre trend & -0.40 & -0.71 to -0.1 & 0.01 & -0.11 & -0.37 to 0.16 & 0.43 & -0.37 & -0.62 to -0.12 & 0.01 \\
\hline Immediate change & 0.25 & -2.83 to 3.32 & 0.87 & -2.27 & -4.93 to 0.38 & 0.09 & 2.74 & 0.81 to 4.67 & 0.01 \\
\hline Trend change & 0.67 & 0.3 to 1.03 & $<0.01$ & 0.30 & -0.04 to 0.63 & 0.08 & 0.48 & 0.2 to 0.75 & $<0.01$ \\
\hline \multicolumn{10}{|c|}{$6 \mathrm{CCO}$ sithout a significant decrease in proportion of opioid fills $>=90 \mathrm{MME}$ per day } \\
\hline Intercept & 9.92 & 7.04 to 12.79 & $<0.01$ & 3.45 & 2.43 to 4.48 & $<0.01$ & 6.66 & 3.89 to 9.43 & $<0.01$ \\
\hline Pre trend & -0.17 & -0.63 to 0.29 & 0.46 & -0.01 & -0.14 to 0.12 & 0.88 & -0.15 & -0.59 to 0.29 & 0.49 \\
\hline Immediate change & 1.31 & -3.43 to 6.04 & 0.58 & 1.09 & -0.58 to 2.76 & 0.19 & 0.13 & -3.74 to 4.01 & 0.94 \\
\hline Trend change & 0.33 & -0.19 to 0.86 & 0.20 & 0.10 & -0.1 to 0.3 & 0.31 & 0.24 & -0.22 to 0.7 & 0.30 \\
\hline
\end{tabular}

MME Morphine milligram equivalents, CCO coordinated care organization, $\mathrm{Cl}$ confidence interval

enrollees per month; $95 \%$ CI 0.16 to $0.64 ; ;<0.01$ ). For each outcome, the increase was large enough to reverse the previously declining overdose rates.

Supplemental Table 2 summarizes ITS regression estimates for each $\mathrm{CCO}$ for the proportion of opioid prescriptions above $90 \mathrm{MME}$ per day. The trend in percentage of opioid prescriptions over 90 MME per day declined significantly in 10 of 16 CCOs. Table 2 also summarizes ITS regression models for opioid overdose for the ten CCOs that had significant decline in the trend of opioid prescriptions over $90 \mathrm{MME}$ per day and six that did not. Among the $10 \mathrm{CCOs}$ that had reductions in high-dose opioid prescriptions, the trend in opioid overdose increased significantly (0.67 events per 100,000 enrollees per month; $95 \%$ CI 0.3 to $1.03 ; p<0.01$ ). These changes were largely driven by the significant increase in non-heroin involved overdose trends (0.48 events per 100,000 enrollees per month; $95 \%$ CI 0.2 to 0.75 ; $p<0.01)$. Although overdose rates also increased among the $6 \mathrm{CCOs}$ that did not have reductions in their high dose opioid use, these changes were not statistically significant. Changes in heroin-involved overdose were not statistically significant when stratified by CCO groups.

\section{Discussion}

States, healthcare systems, and payers have mounted diverse responses to the opioid epidemic. A common approach has been restrictions on opioid prescribing through development and adoption of prescription drug monitoring programs, clinical practice guidelines, and legal and payer strategies to limit certain types of opioid prescribing. However, the evidence that supply-side restrictions on opioid prescribing are effective at reducing opioid overdose has been mixed [3, 4].

In 2015, Oregon implemented an innovative performance improvement project across its 16 CCOs aimed at reducing high-dose opioid prescribing. Similar to national trends [18], overall and high-dose opioid prescribing prior to the implementation of the project were already in decline. Following introduction of the state's high-dose initiative, we found the trajectory of high-dose opioid prescriptions, as a proportion of all opioid prescriptions, declined significantly. This reduction was a combination of an immediate reduction and continued decline in high-dose prescriptions observed following implementation of the state's performance improvement project. Despite lower use of high-dose opioid prescriptions, we found no evidence the project was associated with reductions in opioid-related overdose hospitalizations. In contrast, there were significant increases in the trend for total, heroin-involved, and non-heroin involved opioid poisonings following the project's implementation. Increases in opioid-related overdose trends were most pronounced among the ten CCOs that exhibited significant reductions in the proportion of high-dose opioid prescriptions.

Like the Oregon Medicaid policy initiative, many states have adopted guidelines or enacted laws that place explicit limits on opioid prescriptions [19]. Although evaluations of these initiatives have generally shown 
them to be effective at reducing different aspects of prescription opioid use, their effect on health outcomes is unclear. In 2007, the state of Washington became the first governmental authority to develop and implement opioid dosing guidelines that specifically cautioned against prescribing opioids over a specific dose threshold (120 MME per day). Several studies have found that implementation of the original guideline and subsequent iterations was associated with fewer high-dose prescriptions in the workers compensation and Medicaid programs [20-22]. Another state-level ecologic study found that states that implemented dose-related opioid prescribing guidelines (including Washington) had significant reductions for trends in hospitalization for opioid overdose compared to comparison states [23].

Public and commercial healthcare payers have also introduced polices such as prior authorization and quantity limits that are intended to limit opioid prescriptions [3, 4, 24-26]. In general, utilization management policies directed at opioid prescribing have been shown to have potent effects on opioid prescribing [27-31]. However, the effect of these payer strategies on opioidrelated outcomes has also been mixed. Restrictions on high-dose and long-acting opioid use in two state Medicaid programs was associated with fewer high-risk opioid prescriptions, but was not associated with fewer opioid overdoses [30, 31]. However, another study found that Medicaid plans with more prior authorization policies had lower rates of opioid overdose [32].

In addition to the lack of strong evidence supporting policies restricting prescription opioid use on health outcomes, there have been growing concerns that supply side efforts to reduce opioid misuse, addiction, and overdose are challenging for patients with chronic pain, dependence, or untreated opioid use disorder if they are discontinued from opioid therapy. Qualitative research conducted among individuals with chronic pain indicate that prescription policies aimed at reducing opioid prescribing can have negative effects on patient stigmatization and fears of untreated pain [33, 34]. In a qualitative study involving individuals with a prior prescription opioid overdose, Mueller et al. found patients with chronic pain who experienced opioid-related policy restrictions sometimes engaged in higher risk behavior in attempts to manage pain exacerbations that included not taking pain medications as prescribed, co-administering with other substances such as alcohol, or illicitly obtaining opioids [34]. A growing number of quantitative studies have begun to examine the effect of restrictive opioid policies on potential unintended outcomes such as transition to illicit opioids, overdose, or self-harm. In a large cohort of prescription opioid users in the Veterans Health Administration reported that individuals who discontinued opioid therapy were at a higher risk of death from overdose or suicide relative to individuals who continued opioid therapy [5]. Another study in the Vermont Medicaid program found rapidity of dose reduction was associated with an increased risk of opioid-related adverse events among those who were discontinued from chronic opioid therapy [6]. A case-control study from a large integrated health care network found a two-fold higher odds of prescription opioid discontinuation among individuals who used heroin relative to non-heroin users [7].

Since the study period, Oregon has increased efforts to expand access to substance use disorder treatment, recovery support, and harm reduction tools, including through securing federal grants, investing state resources, and implementing policy changes. Our study suggests prescription opioid policy restrictions are insufficient in achieving reductions in overall overdose rates, and investment in a broader array of supports related to opioid use disorder is needed. Evidence has also grown supporting the use of buprenorphine therapy in opioid tapering protocols among patients without a diagnosis of opioid use disorder [35, 36].

This study has limitations. First, our study did not include a control group and therefore that observed reductions may have been affected by other secular trends in prescribing. Another methodologic limitation concerns the transition from ICD9 to ICD10 that occurred in October 2015, about the same time as the CCO initiative. However, in a national study hospitalization data admissions for poisonings actually declined following the transition which suggests the increases we observed may be conservative [37]. Our analyses were confined to Medicaid pharmacy claims data and did not capture opioid prescriptions that were paid for out-ofpocket [38]. It is possible that efforts to reduce high dose prescriptions were circumvented by patients paying cash for prescriptions where policy barriers were meant to restrict access.

It is also conceivable the rising overdose ED visits and hospitalizations were driven by fentanyl involvement. Illicit fentanyl has been the major contributor to rising opioid-related deaths over the last several years [39]. Nationally, deaths attributed to synthetic opioids, such as fentanyl, have quadrupled from 3.1 to 11.4 deaths per 100,000 from 2015 to 2019 [40]. Although, until recently, much of this rise has been concentrated in communities east of the Mississippi River, western parts of the US are now experiencing surges in fentanyl-involved deaths [41]. According to data from Oregon State Medical Examiner, fentanyl-related fatalities have increased three-fold from 0.399 to 1.464 deaths per 100,000 between 2015 and 2019 [42]. Fentanyl poisoning is normally coded in ICD10 as T40.4 "Poisoning by synthetic narcotics." Although the 
validity of administrative data to identify opioid overdoses has been established, the specificity of ICD-10 data to correctly identify overdoses attributable to illicit fentanyl is unclear [43]. We attempted to separately analyze opioid-involved overdoses involving synthetics (ICD10 T40.4) and found they only accounted for about $5 \%$ of total opioid-related overdoses since October 2015. Finally, we did not examine other clinical consequences of policies which limit opioid supply such as inadequate pain control, suicide/suicidal ideation, and use of illicit drugs.

\section{Conclusions}

Efforts to confront the opioid epidemic have often focused on reducing risks associated with prescription opioids, such as high-dose prescribing. We found that implementation of a quality improvement program aimed at reducing high-dose opioid prescribing across Oregon's CCOs was associated with declines in these high-risk prescriptions. While rates of opioid overdose increased following the program's implementation, the causal link between these two disparate trends remains murky because of the concurrent rise of fentanylinvolved poisonings in the West, which may not be fully delineated in administrative claims [44]. It is also possible that the intent of the policy was blunted by rising outof-pocket payments for opioids, which are relatively low cost. With growing concerns about potential substitution of prescription opioids with those from illicit sources, our findings further underscore the limitations of supply-side efforts to combat a public health crisis that has evolved beyond prescription opioids.

\section{Abbreviations}

CCO: Coordinated Care Organization; ED: Emergency department; ICD: International Classification of Disease; ITS: Interrupted Time Series; MME: Morphine Milligram Equivalent.

\section{Supplementary Information}

The online version contains supplementary material available at https://doi. org/10.1186/s12913-022-07477-6.

Additional file 1.

\section{Acknowledgements}

Not applicable.

\section{Disclosures}

This work was funded by the CDC. Investigators report no financial conflicts of interest.

\section{Authors' contributions}

DMH: study conception, acquisition of data, interpretation of data, drafted and revised manuscript. JG: data analysis and interpretation, revised manuscript. SEH: data interpretation, revised manuscript. PTK: data interpretation, revised manuscript. LM: revised manuscript. GL: data interpretation, revised manuscript. $\mathrm{CH}$ : data interpretation, revised manuscript. HK: data analysis, interpretation of data, revised manuscript. All authors have approved the submitted manuscript. All authors have agreed both to be personally accountable for the author's own contributions and to ensure that questions related to the accuracy or integrity of any part of the work, even ones in which the author was not personally involved, are appropriately investigated, resolved, and the resolution documented in the literature.

\section{Funding}

This paper was supported by the US Centers for Disease Control (U01 CE002786). CDC had no role the design of the study and collection, analysis, and interpretation of data and in writing the manuscript.

\section{Availability of data and materials}

The datasets generated and/or analyzed during the current study are not publicly available because of terms of the data use agreement.

\section{Declarations}

Ethics approval and consent to participate

All methods were carried out in accordance with relevant guidelines and regulations. This study was approved by the institutional review board at the Oregon Health \& Science University (OHSU). The OHSU IRB granted a waiver of informed consent for this study.

\section{Consent for publication}

Not applicable.

\section{Competing interests}

Authors report no relevant financial conflicts of interest.

\section{Author details}

${ }^{1}$ Oregon State University, College of Pharmacy, 2730 S Moody Ave., CL5CP, Portland, OR 97201, USA. ²Oregon Health \& Science University, 3181 SW Sam Jackson Park Rc, Portland, Oregon 97239, USA. ${ }^{3}$ Comagine Health, 650 NE Holladay St., Portland, OR 97232, USA.

Received: 1 September 2021 Accepted: 31 December 2021

Published online: 14 January 2022

\section{References}

1. Aitken M. Medicine use and spending in the U.S. A Review of 2018 and Outlook to 2023; 2019.

2. Scholl L, Seth P, Kariisa M, Wilson N, Baldwin G. Drug and opioid-involved overdose deaths - United States, 2013-2017. MMWR Morb Mortal Wkly Rep. 2018;67(5152):1419-27.

3. Haegerich TM, Jones CM, Cote PO, Robinson A, Ross L. Evidence for state, community and systems-level prevention strategies to address the opioid crisis. Drug Alcohol Depend. 2019;204:107563.

4. Mauri Al, Townsend TN, Haffajee RL. The Association of State Opioid Misuse Prevention Policies with Patient- and Provider-Related Outcomes: a scoping review. Milbank Q. 2020;98(1):57-105.

5. Oliva EM, Bowe T, Manhapra A, Kertesz S, Hah JM, Henderson P, et al. Associations between stopping prescriptions for opioids, length of opioid treatment, and overdose or suicide deaths in US veterans: observational evaluation. BMJ. 2020;368:m283.

6. Mark TL, Parish W. Opioid medication discontinuation and risk of adverse opioid-related health care events. J Subst Abus Treat. 2019;103:58-63.

7. Binswanger IA, Glanz JM, Faul M, Shoup JA, Quintana LM, Lyden J, et al. The association between opioid discontinuation and heroin use: a nested case-control study. Drug Alcohol Depend. 2020;217:108248.

8. 2019;Pageshttps://www.oregon.gov/oha/PH/PREVENTIONWELLNESS/ SUBSTANCEUSE/OPIOIDS/Pages/data.aspx on November 13, 2019.

9. Hartung DM, Kim H, Ahmed SM, Middleton L, Keast S, Deyo RA, et al. Effect of a high dosage opioid prior authorization policy on prescription opioid use, misuse, and overdose outcomes. Subst Abus. 2018;39(2):239-46. 
10. Hedberg K, Bui LT, Livingston C, Shields LM, Van Otterloo J. Integrating public health and health care strategies to address the opioid epidemic: the Oregon health Authority's opioid initiative. J Public Health Manag Pract. 2019;25(3):214-20.

11. McConnell KJ. Oregon's Medicaid Coordinated Care Organizations. JAMA 2016;315:869-70.

12. Oregon Health Authority. Office of Clinical Services Improvement: Statewide Performance Improvement Project. http://www.oregon.gov/OHA/ HPA/CSI/pages/Performance-Improvement-Project.aspx. Accessed 31 Aug 2017.

13. Hartung DM, Alley L, Leichtling G, Korthuis PT, Hildebran C. A statewide effort to reduce high-dose opioid prescribing through coordinated care organizations. Addict Behav. 2018;86:32-9.

14. Logan J, Liu Y, Paulozzi L, Zhang K, Jones C. Opioid prescribing in emergency departments: the prevalence of potentially inappropriate prescribing and misuse. Med Care. 2013;51(8):646-53.

15. Dowell D, Haegerich TM, Chou R. CDC Guideline for Prescribing Opioids for Chronic Pain--United States, 2016. Jama. 2016;315(15):1624-45.

16. 2016;Pages. Accessed at Centers for Disease Control and Prevention at http://www.pdmpassist.org/pdf/BJA_performance_measure_aid_MME_ conversion.pdf on March 23, 2017.

17. Linden A. Conducting interrupted time-series analysis for single- and multiple-group comparisons. Stata J. 2015;15(2):480-500.

18. Centers for Disease Control and Prevention. 2018 Annual Surveillance Report of Drug-Related Risks and Outcomes — United States. Surveillance Special Report. Centers for Disease Control and Prevention, U.S. Department of Health and Human Services. Published August 31, 2018. Accessed 21 Nov 2019. from https://www.cdc.gov/drugoverdose/pdf/ pubs/2018-cdc-drug-surveillance-report.pdf.

19. Davis CS, Lieberman AJ, Hernandez-Delgado H, Suba C. Laws limiting the prescribing or dispensing of opioids for acute pain in the United States: a national systematic legal review. Drug Alcohol Depend. 2019;194:166-72.

20. Fulton-Kehoe D, Sullivan MD, Turner JA, Garg RK, Bauer AM, Wickizer TM, et al. Opioid poisonings in Washington state Medicaid: trends, dosing, and guidelines. Med Care. 2015;53(8):679-85.

21. Franklin GM, Mai J, Turner J, Sullivan M, Wickizer T, Fulton-Kehoe D. Bending the prescription opioid dosing and mortality curves: impact of the Washington state opioid dosing guideline. Am J Ind Med. 2012;55(4):325-31.

22. Sears JM, Haight JR, Fulton-Kehoe D, Wickizer TM, Mai J, Franklin GM. Changes in early high-risk opioid prescribing practices after policy interventions in Washington State. Health Serv Res. 2021;56(1):49-60.

23. Sears JM, Fulton-Kehoe D, Schulman BA, Hogg-Johnson S, Franklin GM. Opioid overdose hospitalization trajectories in states with and without opioid-dosing guidelines. Public Health Rep. 2019;134(5):567-76.

24. Lin DH, Jones CM, Compton WM, Heyward J, Losby JL, Murimi IB, et al. Prescription drug coverage for treatment of low Back pain among US Medicaid, Medicare advantage, and commercial insurers. JAMA Netw Open. 2018;1(2):e180235.

25. Gifford K, Ellis E, Edwards BC, Lashbrook A. Medicaid moving ahead in uncertain times: results from a 50-state medicaid budget survey for state fiscal years 2017 and 2018. Menlo Park: Kaiser Family Foundation; 2017. https://www.kff.org/medicaid/report/medicaid-moving-ahead-in-uncer tain-times-results-from-a-50-state-medicaidbudget-survey-for-state-fiscal-years-2017-and-2018/. Accessed 13 Jan 2022.

26. Samuels EA, Ross JS, Dhruva SS. Medicare formulary coverage restrictions for prescription opioids, 2006 to 2015. Ann Intern Med. 2017;167(12):895-6.

27. García MC, Dodek AB, Kowalski T, Fallon J, Lee SH, lademarco MF, et al. Declines in opioid prescribing after a private insurer policy change - Massachusetts, 2011-2015. MMWR Morb Mortal Wkly Rep. 2016;65(41):1125-31.

28. Morden NE, Zerzan JT, Rue TC, Heagerty PJ, Roughead EE, Soumerai SB, et al. Medicaid prior authorization and controlled-release oxycodone. Med Care. 2008;46(6):573-80.

29. Riggs CS, Billups SJ, Flores S, Patel RJ, Heilmann RM, Milchak JL. Opioid use for pain management after implementation of a Medicaid short-acting opioid quantity limit. J Manag Care Spec Pharm. 2017;23(3):346-54.

30. Hartung DM, Kim H, Ahmed SM, Middleton L, Keast S, Deyo RA, et al. Effect of a high dosage opioid prior authorization policy on prescription opioid use, misuse, and overdose outcomes. Subst Abus. 2018;39:239-46.
31. Keast SL, Kim H, Deyo RA, Middleton L, McConnell KJ, Zhang K, et al. Effects of a prior authorization policy for extended-release/long-acting opioids on utilization and outcomes in a state Medicaid program. Addiction. 2018;113:1651-60.

32. Cochran G, Gordon AJ, Gellad WF, Chang CH, Lo-Ciganic WH, Lobo C, et al. Medicaid prior authorization and opioid medication abuse and overdose. Am J Manag Care. 2017;23(5):e164-e71.

33. Antoniou T, Ala-Leppilampi K, Shearer D, Parsons JA, Tadrous M, Gomes T. "Like being put on an ice floe and shoved away": a qualitative study of the impacts of opioid-related policy changes on people who take opioids. Int J Drug Policy. 2019;66:15-22.

34. Mueller SR, Glanz JM, Nguyen AP, Stowell M, Koester S, Rinehart DJ, et al. Restrictive opioid prescribing policies and evolving risk environments: a qualitative study of the perspectives of patients who experienced an accidental opioid overdose. Int J Drug Policy. 2021;92:103077.

35. Chou R, Ballantyne J, Lembke A. Rethinking Opioid Dose Tapering, Prescription Opioid Dependence, and Indications for Buprenorphine. Ann Intern Med. 2019;171:427-9.

36. Robbins JL, Englander H, Gregg J. Buprenorphine microdose induction for the Management of Prescription Opioid Dependence. J Am Board Fam Med. 2021;34(Suppl):S141-s6.

37. Heslin KC, Owens PL, Karaca Z, Barrett ML, Moore BJ, Elixhauser A. Trends in opioid-related inpatient stays shifted after the US transitioned to ICD10-CM diagnosis coding in 2015. Med Care. 2017;55(11):918-23.

38. El Ibrahimi S, Hallvik S, Johnston K, Leichtling G, Choo E, Hartung DM. A comparison of trends in opioid dispensing patterns between Medicaid pharmacy claims and prescription drug monitoring program data. Pharmacoepidemiol Drug Saf. 2020;29(9):1168-74.

39. Ciccarone D. The rise of illicit fentanyls, stimulants and the fourth wave of the opioid overdose crisis. Curr Opin Psychiatry. 2021;34(4):344-50.

40. Hedegaard H, Miniño AM, Warner M. Drug overdose deaths in the United States, 1999-2019. NCHS Data Brief. 2020;394:1-8.

41. Shover CL, Falasinnu TO, Dwyer CL, Santos NB, Cunningham NJ, Freedman RB, et al. Steep increases in fentanyl-related mortality west of the Mississippi River: recent evidence from county and state surveillance. Drug Alcohol Depend. 2020;216:108314.

42. 2021;Pages. Accessed at Oregon Health Authority at https://www.oregon. gov/oha/PH/PREVENTIONWELLNESS/SUBSTANCEUSE/OPIOIDS/Pages/ data.aspx on May 20, 2021.

43. Green CA, Perrin NA, Janoff SL, Campbell Cl, Chilcoat HD, Coplan PM. Assessing the accuracy of opioid overdose and poisoning codes in diagnostic information from electronic health records, claims data, and death records. Pharmacoepidemiol Drug Saf. 2017;26(5):509-17.

44. Mattson CL, Tanz LJ, Quinn K, Kariisa M, Patel P, Davis NL. Trends and geographic patterns in drug and synthetic opioid overdose deaths - United States, 2013-2019. MMWR Morb Mortal Wkly Rep. 2021;70(6):202-7.

\section{Publisher's Note}

Springer Nature remains neutral with regard to jurisdictional claims in published maps and institutional affiliations.

$$
\begin{aligned}
& \text { Ready to submit your research? Choose BMC and benefit from: } \\
& \text { - fast, convenient online submission } \\
& \text { - thorough peer review by experienced researchers in your field } \\
& \text { - rapid publication on acceptance } \\
& \text { - support for research data, including large and complex data types } \\
& \text { - gold Open Access which fosters wider collaboration and increased citations } \\
& \text { - maximum visibility for your research: over } 100 \mathrm{M} \text { website views per year }
\end{aligned}
$$

At BMC, research is always in progress.

Learn more biomedcentral.com/submissions 